Intersections

Canadian Journal of Music

Revue canadienne de musique
Intersections CANADIAN JOURAL OF MUSIC
REVUE CANADIENEE DE MUSIOUH

\title{
Predictors of Piano Student Dropouts
}

\section{Karen Gerelus, Gilles Comeau et Mikael Swirp}

Volume 37, numéro 2, 2017

URI : https://id.erudit.org/iderudit/1066616ar

DOI : https://doi.org/10.7202/1066616ar

Aller au sommaire du numéro

\section{Éditeur(s)}

Canadian University Music Society / Société de musique des universités canadiennes

ISSN

1911-0146 (imprimé)

1918-512X (numérique)

Découvrir la revue

Citer cet article

Gerelus, K., Comeau, G. \& Swirp, M. (2017). Predictors of Piano Student Dropouts. Intersections, 37(2), 27-42. https://doi.org/10.7202/1066616ar

\section{Résumé de l'article}

Abandonner les cours de piano avant d'atteindre une maîtrise raisonnable de l'instrument est un problème fréquent parmi les étudiants. De précédentes recherches ont montré que les enfants décrochent des leçons de musique à la lumière de facteurs tels que l'expertise - mesurée par l'habilité musicale, l'accomplissement académique, et l'accomplissement musical - et l'environnement - mesurée le statut social et éducationnel, les différences de genre, l'investissement parental, et la culture à la maison. Cinquante-cinq anciens étudiants en piano et leurs parents ont rempli des questionnaires contenant des questions selon l'échelle de Likert, à choix multiple, et à réponse ouverte dans le cadre d'une étude en méthodes mixtes. Ce groupe a été comparé à cent cinquante-trois étudiants et parents qui poursuivaient encore leurs leçons. Les résultats entre ces deux groupes montrent que plusieurs facteurs d'attrition soulignés dans la littérature ont également prédit le décrochage des étudiants en piano.
Copyright ( C Canadian University Music Society / Société de musique des universités canadiennes, 2019
Ce document est protégé par la loi sur le droit d'auteur. L'utilisation des services d'Érudit (y compris la reproduction) est assujettie à sa politique d'utilisation que vous pouvez consulter en ligne.

https://apropos.erudit.org/fr/usagers/politique-dutilisation/ 


\title{
PREDICTORS OF PIANO STUDENT DROPOUTS
}

\author{
Karen Gerelus, Gilles Comeau, and Mikael Swirp
}

\section{INTRODUCTION}

A recurring topic of discussion among parents, teachers, and researchers is the problem of piano students who begin lessons, only to give up a short time later. There are frequent informal debates among studio teachers about the reasons why students leave piano lessons before reaching even a moderate mastery of the instrument. Teacher Ruthie Gray (2016) believes that not all children are meant to be musicians and not "having a knack for it" leads to dropout. Kent Moore (2012) writes that teachers are responsible for the motivation that keeps students engaged in lessons. Theresa Chen (2011) has observed that "young students start out extremely enthusiastic about music, then lose interest, then go through a zig-zag of motivation, gain interest again, then quit" (para. 1). There seem to be as many opinions as there are publications regarding reasons for piano student dropout. Despite the vast amount of speculation in pedagogical debates, there is a modest amount of research literature that gives insight to this topic.

In general, researchers agree that there is "an alarmingly high proportion" of students who began to learn an instrument and subsequently abandoned this effort (North, Hargreaves, and O’Neill 2000, 270). Music students often give up before reaching even a modest competency, "dissatisfied with the learning experience and disillusioned with music activities" (Evans 2009, 19). Research has found that piano students "begin their lessons willingly, even enthusiastically, yet many discontinue their lessons before reaching a level of accomplishment that would allow the musical independence and satisfaction to which they aspire" (Costa-Giomi, Flowers, and Sasaki 2005, 235). However, specific to piano lessons, there is "a paucity of material that provides evidence-based insights into what factors influence whether a student continues to the advanced stage or ceases learning" (Daniel and Bowden 2013, 246). Recent discussion has suggested that quitting lessons before reaching a moderate mastery of the piano is a concern, because "dropping out prematurely from music instruction may preclude students from experiencing the full benefits of music learning" (Cremaschi et al. 2015, 15).

It is recognized that many piano students quit lessons before even reaching a moderate mastery of the piano, and the pre-teen or early adolescent years seem to be the major point of dropout (Barry 2007; Seo 2010). Researchers 
Daniel and Bowden (2013) found more than half of the music teachers surveyed believe the early teenage stage of piano learning "involves a high drop-out rate" (255). Literature has demonstrated that as piano students grow older, they become fewer, such that "the percentage of boys taking lessons dropped from $33.6 \%$ when they were 9 years old, to $9.8 \%$ when they were 17 " (Cremaschi et al. 2015, 15). In Britain, research found that young children start out very enthusiastic to learn an instrument, but only $12 \%$ of 11 -year-olds, and later $4 \%$ of 14-year-olds, share that same interest (Cooke and Morris, 1996). Evans (2009) also found a gradual increase in music student dropout over time, but the first sudden and significant surge of dropout comes at age 11. It seems that both teachers and researchers agree that a significant percentage of piano students quit in the pre-teen and early adolescent years.

Although when students quit is a compelling discussion, why is arguably more valuable. It seems that there are certain factors in place before the students begin lessons that predict whether or not students will continue with their musical education. Previous research with school band and classroom music student dropouts has shown that predictors of academic achievement (Young 1971; Frakes 1984; Klinedinst 1991), socio-economic status (McCarthy 1980), and musical ability (Mawbey 1973; Asmus 1986) show valid projections of music student retention or dropout. Research showed that the approval-seeking piano students who required frequent, external positive feedback were likely to quit, and suggests that insecure behavioural differences related to low musical achievement can identify dropouts (Costa-Giomi, Flowers, and Sasaki 2005). Differences in gender attributes suggest that boys may be more disinterested or discouraged from playing a "feminine" instrument such as the piano (Griswold and Chroback 1981), or participating in music generally (Croucher and Reid 1981; Cooke and Morris 1996), and more recent research has shown that male students generally find music classes less important or useful than female students do (McPherson et al. 2015). It seems that piano students who had distant, demanding, or disinterested parents were also prone to dropping out (Govel 2004; Chardos-Camilli 2010). Further, there has been some evidence to suggest that Asian-heritage piano students display higher levels of autonomous motivation (Comeau, Huta, and Liu 2015) and higher levels of achievement (Power 1990) than their Caucasian counterparts, have proven to be successful in many international competitions (Yang 2009), and are heavily recruited by North American universities and conservatories, viewed as "model international students" (Brand 2001). These factors combine to suggest that Asian-heritage students are less likely to drop out and have home and cultural environments more conducive to piano study. Since research has focused primarily on classroom music and school band students, it is not clear if these same attributes apply to private piano students as well.

\section{Research Question AND Methodology}

The research completed in orchestral and band settings provides a good foundation for the topic of piano student dropouts, but further study specific to 
private lessons is needed. The research that is focused on dropouts with band and orchestral instrument students is not sufficient to be generalized to piano students, because the challenges of individual lessons are different from those in group settings. Some notable differences include factors such as difficult solo repertoire, close teacher relationship, lack of a social group aspect, and a large extracurricular time commitment. School bands also tend to work on a variety of repertoire such as Broadway musicals, popular songs, and holiday music, whereas piano lessons are still focused mainly in the classical tradition. Our study was part of a larger research project involving former piano students, which examined both student motivation and predictors of dropout. The results regarding motivation have been presented elsewhere (Gerelus, Comeau, Huta, and Swirp, 2019) and, as such, this article will focus on the predictors. This is the first study to compare dropout and continuing piano students while discussing the predictors of attrition, and includes a broad number of participants from across Canada (see Costa-Giomi 2004 for a smaller-scale comparison in the United States).

We were interested to know if the factors that led to dropout in classroom band students also applied to private piano students. From the literature reviewed, it seems that there are two overarching categories that lead to dropout: expertise-measured by musical ability, academic achievement, and musical achievement-and environment-measured by social and educational status, gender differences, parental involvement, and home culture.

QUESTION: What is the role of expertise and environment in students' decisions to drop out of piano lessons?

HYPOTHESIS: Since expertise and environment play a role in dropping out of classroom music programs, we expect the same effect of these factors in the private piano studio. We also expect to find differences for these factors between continuing and dropout groups.

\section{Participants}

There were 55 former piano students, along with their parents, who made up the dropout group. This consisted of 34 female and 21 male, primarily white, Canadian students. Students' ages ranged between 8 and 17.5 years old, with an average of 13.1 years old (see table 1). Dropout students began lessons at approximately 7 years old and took lessons for an average of 5 years until around age 12. It is notable that an average age 12 upon quitting lessons confirms the commonly held belief of the pre-teen dropout stage. Their piano lessons ended an average of 1 year prior to taking the survey.

This group was compared with 153 current piano students who planned to continue their lessons. Continuing students consisted of 100 female and 53 male students, of whom one-third had Asian-Canadian background (see table 2). Continuing students ranged in age between 6 and 20 years old, with an average of 11 years old. Students in this group began lessons, on average, at 6.3 years old and had taken lessons for an average of 4.76 years at the time they completed the survey. 
Table 1. Descriptive statistics of piano students.

\begin{tabular}{|c|c|c|c|c|c|c|c|c|}
\hline & \multicolumn{4}{|c|}{ Continuing students } & \multicolumn{4}{|c|}{ Dropout students } \\
\hline & $n$ & Range & $M$ & $S D$ & $n$ & Range & $M$ & $S D$ \\
\hline Age started lessons & 153 & 3.0 to 12.0 & 6.27 & 2.03 & 55 & 3.0 to 13.5 & 6.96 & 2.11 \\
\hline Age stopped lessons & & & & & 54 & 8.0 to 17.5 & 12.04 & 2.34 \\
\hline Years of lessons & 153 & 0.5 to 13.5 & 4.76 & 2.82 & 54 & 1.0 to 10.0 & 4.93 & 2.26 \\
\hline Current age & 153 & 6.0 to 20.0 & 11.00 & 2.68 & 55 & 8.0 to 17.6 & 13.11 & 2.45 \\
\hline
\end{tabular}

Note: $n=$ sample size; $M=$ mean; $S D=$ standard deviation

Table 2. Comparison of ethnicity between continuing and dropout groups.

\begin{tabular}{lcc}
\hline & Continuing $(n)$ & Dropouts $(n)$ \\
\hline Mother's ethnicity & 90 & 44 \\
Caucasian & 45 & 6 \\
East Asian & 18 & 5 \\
Other & & \\
\hline Father's ethnicity & 84 & 41 \\
Caucasian & 49 & 8 \\
East Asian & 20 & 6 \\
Other & & \\
\hline
\end{tabular}

\section{Procedure}

Researchers contacted members of various professional music teachers' associations in Canada, who were then asked to contact their former students, distribute invitation letters, and gain permission to forward the parents' contact information back to the researchers. Continuing students were recruited in a similar way. Both continuing and dropout participants had taken formal piano lessons with a professional teacher for at least one academic year. Dropout students had quit piano lessons within the previous year and were considered eligible participants for this study, even if they continued lessons on a different instrument.

This study used the Survey of Musical Interests (2005) developed by the Piano Pedagogy Research Laboratory at the University of Ottawa and was chosen for this study because of ability to address the predictors outlined in the literature. We opted for multiple-choice, open-ended, and Likert-scale questions in a mixed-methods study (Creswell 2015). Children reported their opinions and experiences with piano lessons, and parents also answered questions in the same format, but regarding the child's musical background and learning environment. For example, parents were asked, "At home, how often did you (or your spouse) help your child with piano practice?" and responded by choosing $1=$ never, $2=$ seldom, $3=$ sometimes, $4=$ often, $5=$ always. All participants were 
assured of strict confidentiality, that there were no right or wrong answers, and that this study had been approved by the University of Ottawa Research Ethics Board. Questionnaires took place primarily in students' homes, but children and parents answered the questionnaire in separate spaces to avoid undue influence. The data from each student and parent survey were manually entered into the Statistical Package for the Social Science (SPSS) computer program where statistical analyses were performed.

\section{Results}

This section will provide results for the major predictors of dropout, which can be broadly grouped into two themes: expertise which includes musical ability, musical achievement, and academic achievement, and environment which includes social and educational status, gender differences, parental involvement, and home culture.

\section{EXPERTISE}

While we did not administer a standardized musical competency test, researchers measured musical ability and achievement by asking questions regarding rate of progress, parental rating of their child's piano playing ability, amount of effort required for success, and their involvement in piano exams. There was a significant difference between the two groups' rates of progress: students who dropped out had reached significantly lower playing level, despite taking lessons for slightly more time (see table 3 ). After an average of 4.76 years of lessons, the continuing students on average were playing at a Level 4 conservatory standard, while after an average of 4.9 years of lessons, the dropout students were playing at an average of Level 2 conservatory standard. ${ }^{1} \mathrm{Next}$, we asked the students' opinion of their own-or the parent's opinion of their child's-overall musical ability (see table 3). The dropout students acknowledged that their musical ability was not as strong as the continuing students, but their responses still placed them slightly "above average" despite dropping out. Parents answering this same question rated their children even higher than the children themselves. Finally, we measured musical ability by the effort required to succeed at playing the piano (see table 3). Both parents and students within the dropout group responded that they would have to work about the same as most other students to be successful. In contrast, parents and students in the continuing group responded that they would need to work about the same, or even somewhat harder, to be successful.

1 The grade levels referred to in this study are based on the Royal Conservatory of Music (Canada) 2008 Piano Syllabus. 
Table 3. Musical ability and achievement in continuing and dropout groups.

\begin{tabular}{|c|c|c|c|c|c|c|c|}
\hline & \multicolumn{3}{|c|}{ Continuing } & \multicolumn{2}{|c|}{ Dropout } & \multicolumn{2}{|c|}{ Statistical results } \\
\hline & Scale & M & $S D$ & M & $S D$ & $t$ & $d f$ \\
\hline \multicolumn{8}{|c|}{ Musical achievement } \\
\hline Grade level & 0 to 11 & 4.44 & 3.25 & 2.46 & 2.34 & $4.291^{* * *}$ & 122.7 \\
\hline $\begin{array}{l}\text { Rate of progress } \\
\text { (grades/year) }\end{array}$ & & 0.73 & 0.46 & 0.45 & 0.4 & $3.598^{* * *}$ & 151 \\
\hline \multicolumn{8}{|c|}{ Piano playing ability } \\
\hline Child's rating & 1 to 5 & 3.61 & 0.8 & 3.15 & 0.78 & $3.739^{\star * *}$ & 98.17 \\
\hline Parent's rating & 1 to 5 & 3.59 & 0.74 & 3.4 & 0.53 & $2.106^{*}$ & 125.6 \\
\hline \multicolumn{8}{|l|}{$\begin{array}{l}\text { Required effort to } \\
\text { succeed at piano }\end{array}$} \\
\hline Child's rating & 1 to 3 & 2.46 & 0.57 & 2.16 & 0.54 & $3.497^{* * *}$ & 101.5 \\
\hline Parent's rating & 1 to 3 & 2.31 & 0.57 & 2.05 & 0.4 & $3.544^{* * *}$ & 135.2 \\
\hline
\end{tabular}

${ }^{*} p<0.05 ;{ }^{* *} p<0.01 ;{ }^{* * *} p<0.001$

Note. $M=$ mean, $S D=$ standard deviation

The next predictor, academic ability, was non-significant and the results will not be reported in detail here. The researchers did not have access to participants' academic records from school, but parents were asked to assess their children's overall academic abilities. All parents from both groups responded that their children's academic abilities were generally higher than average. While low academic ability was previously shown to be a predictor of music student dropout, it seems that very few piano students were described by their parents to have low academic abilities, and that academic ability, as reported by parents, had no effect on the decision to discontinue piano lessons.

\section{ENVIRONMENT}

Social and educational status were gathered by asking the parents' occupation and level of academic study. We chose not to collect data on the economic status of participants; we were more interested in the cultural role of profession and education. While the fathers' occupations and degree of education seemed not to have a significant role, the mothers were more influential. Within the mothers' occupations, researchers found a statistically significant difference such that the dropout group had much higher instances of stay-at-home mothers and it was marginally significant that the dropout group had fewer academic or professional mothers (see table 4). There were also important findings between the mothers' academic degrees, such that the dropout group's mothers were overall less educated. 
Table 4. Comparison of occupation and academic degrees in continuing and dropout groups.

\begin{tabular}{llcl}
\hline & \multicolumn{1}{c}{$\begin{array}{c}\text { Number or mean and standard } \\
\text { deviations }\end{array}$} & $\begin{array}{c}\text { Statistical } \\
\text { results }\end{array}$ \\
\hline Father's occupation & Continuing & Dropout & \\
Academic or professional & 115 & 42 & $X^{2}=0.39$ \\
Trades or diploma & 21 & 10 & \\
\hline Mother's occupation & & & \\
Academic or professional & 107 & 34 & $X^{2}=3.54^{\dagger}$ \\
Trades or diploma & 29 & 18 & \\
\hline Stay-at-home mothers & & & \\
Yes & 17 & 13 & $X^{2}=5.14^{*}$ \\
No & 136 & 42 & \\
\hline Academic degree & & & $t=2.38^{*}$, \\
Mother & $M=3.11$ & $M=2.75$ & $d f=206$ \\
& $S D=1.02$ & $S D=0.82$ & $t=1.38$, \\
Father & $M=3.12$ & $M=2.87$ & $d f=205$ \\
\hline
\end{tabular}

${ }^{\dagger} p<0.1 ;{ }^{*} p<0.05$

Note: $M=$ mean, $S D=$ standard deviation. Academic degree was rated on a 1 (high school) to 5 (PhD) scale.

We anticipated that there would be differences between genders within the dropout group. Despite testing for rate of progress, day and minutes per week of practice, how long they might continue piano lessons, overall years of lessons, their own ratings of musical ability, and sense of a future musical self, we found no difference between boys and girls. Since none of these results were significant, they will not be reported in detail here, but will be discussed later.

Parental involvement was anticipated to be a major predictor of student dropouts, however almost none of the results were significant. The rate at which parents attended piano lessons alongside their children, contacted the piano teacher outside of lessons, or helped with practice at home was similar between continuing and dropout groups. However, since parents primarily determine the daily musical environment, researchers asked what types of music the family listened to and how often they attend professional classical concerts (see Table 5). The significant findings were that dropout students spent more time listening to pop or country, less time listening to classical, and had fewer attendances at concerts. The continuing students were exactly the inverse. 
Table 5. Home environments of continuing and dropout groups.

\begin{tabular}{lcccccc}
\hline Musical environments & \multicolumn{2}{c}{ Continuing } & \multicolumn{2}{c}{ Dropout } & \multicolumn{3}{c}{ Statistical results } \\
\cline { 2 - 7 } & $M$ & $S D$ & $M$ & $S D$ & $t$ & $d f$ \\
\hline Listen to classical music & 2.59 & 1.05 & 2.00 & 1.00 & $3.596^{* * *}$ & 206 \\
Listen to pop music & 3.44 & 1.12 & 3.84 & 0.74 & $-2.906^{* * *}$ & 145 \\
Listen to country or world music & 2.37 & 0.93 & 2.71 & 1.10 & $-2.188^{* *}$ & 206 \\
Listen to jazz music & 1.97 & 0.91 & 2.00 & 1.11 & -0.172 & 206 \\
Attend professional concerts & 2.10 & 1.01 & 1.78 & 0.81 & $2.364^{* *}$ & 118.71 \\
\hline
\end{tabular}

Note: $M=$ mean, $S D=$ standard deviation

Musical environments are based on a 1 to 5 rating scale as follows:

1 = never, 2 = seldom, 3 = sometimes, 4 = often, 5 = always.

\section{Discussion}

\section{Expertise}

Musical achievement had been shown in the literature (Costa-Giomi, Flowers, and Sasaki 2005) to be a predictor of student dropout, and our results suggest the same. Despite taking lessons for slightly more time, the dropout students achieved less and were less proficient than the continuing students. After almost 5 years of lessons, the dropout students were playing only at an average Level 2 conservatory standard, and after an average of 4.76 years of lessons, the continuing students on average were playing at Level 4. To illustrate, this may have meant that, despite being similar in age, the dropout students performed very basic Mozart Minuets alongside their peers who were playing early, but more impressive, Clementi Sonatinas. With a significantly lower level of achievement, dropout students may have reached fewer milestones, had fewer opportunities to perform in recitals, and may not have been eligible for exams or summer music camp participation. Students in our study who may have felt inferior compared to their peers' achievements seemed more likely to drop out.

Academic achievement had been shown in the literature to be a strong predictor of music student dropout (Mawbey 1973; McCarthy 1980; Klinedinst 1991). We must be clear that we did not have access to students' academic school records and the data here are self-evaluated. However, our results showed that dropout students were rated by their parents as above average in academic achievement, which came in disagreement with previous studies, which predicted low academic achievement would be connected with dropouts. One possible explanation is that the previous studies were done with school music settings where anyone can study any instrument without much prior consideration as to achievement, but that it takes the acknowledgement of strong cognitive ability to take on a demanding extracurricular activity such as piano lessons. Instead, our study supported more recent findings done specifically with piano students, which found no differences in cognitive abilities between dropout and continuing groups (Costa-Giomi 2004). We can infer that since 
the dropout students were strong academically, they may have viewed piano lessons as standing in their way to achieving high grades at school. One student wrote that she may "take piano again in the future when I finish school," but for now piano lessons were viewed as interfering with her academic achievement.

A somewhat obvious factor to predict music students' continuation or dropout is musical ability. The literature is divided on whether musical ability is developed by continuous effort or something one is born with. Most studies attribute music ability to outward effort and environment, and suggests that ability is due to "differences in early experiences, preferences, opportunities, habits, training, and practice" (Howe, Davidson, and Sloboda 1998, 399). However, others believe that musical ability is innately rather than circumstantially determined (Gagne 1991). The discussion can be complicated because one group of research is referring to externally developed skill while others are referring to inner talent, and meanwhile all under the heading "ability." More importantly, children who feel they are natural musicians are likely to achieve at a higher level than children who have more negative views about their musical ability (Austin, Renwick, and McPherson 2006). It has been shown that the shift from effort to ability attributions occurs during the sixth and seventh grades, and that "these are grades when teachers often have trouble keeping students involved with music" (Asmus 1986, 275). McPherson and O'Neill (2010) also reported a general decline in competency beliefs and values for school subjects, including music, from the earlier to later years of schooling. This seems to describe the fact that by age 12 the dropout students may have felt they had reached the limit of their natural ability and were not interested in investing further effort.

Children in the dropout group of our study rated their own levels of musical ability significantly lower than the continuing students. One student alluded to their lesser innate musical ability and wished he was "able to play better and had an easier time learning hard pieces." Although their children reached a relatively low playing level and dropped out of piano lessons, parents of dropout students rated their child's music abilities as average or above. Dropout students' parents seemed to be easily satisfied with their children's lesser musical abilities, compared to continuing students, suggesting that parents who have higher expectations of ability development also have children who stay in piano lessons. For example, one parent thought it was reasonable for her daughter "to finish after her Grade 1 exam." Previous research has demonstrated that mothers' higher level of satisfaction with their children's piano lessons may have contributed to their children's relatively low achievement (Power 1990). Similar to our study, this seems to suggest that mothers had lower expectations and were content with less effort. Interestingly, the dropout parents and students also responded that despite their lower natural musical ability, their children needed to work about the same as other students to reach the same level of success. In fact, the dropout students did not work at the same rate as the continuing students: the dropout group practised significantly fewer days per week which, compounded over time, led to less externally developed ability (Gerelus et al., 2019). The students' recognition of their own lower musical ability, paired 
with less than average effort, suggests that both nature and nurture led to a shortfall in musical ability.

\section{Environment}

Our results showed significant findings within the social and educational status of mothers whose children dropped out or continued with piano lessons. The dropout group's mothers had achieved less academically and had far higher percentages of stay-at-home mothers than the continuing group. This comes in contrast to previous research, which found that continuing and dropout piano students were similar in parental occupation and education (Costa-Giomi 2004). It is conceivable that the stay-at-home mothers were less driven to succeed in their own career, had generally lower standards of achievement, creating a different home environment for student learning. The fathers' occupations and educational status did not seem to affect students, which highlights the importance of mother-child interactions in music lessons (McPherson and Davidson 2002). Our results suggest that parents who place a high value on academics, partly as a result of their own high levels of education, will have students who continue with piano lessons. It also speaks to the type of family who enrol and then persist with piano lessons: families who may have read research on the benefits of music lessons, value long-term learning, and have high standards of academic achievement. While any student can take music at school, and much of the literature has focused on classroom music environments, it takes a special interplay of parental education, occupation, and financing to register children for private piano lessons.

The distinction that gender is not connected with dropout is an important finding. These results are imperative to report, since they dispel a common folk belief that the piano lessons are primarily for girls. Despite many of the world's finest pianists being men, it has recently been suggested to piano teachers that "maybe you think every boy has ADD—-maybe you think every girl loves piano" (Kramer 2016, 44). In fact, we could not find any difference in attitudes or habits of male and female piano students, which suggests that either instrumental gender associations are changing, or there has been a historically unfair representation. This stereotype also crosses over into the public education domain, such that "gender stereotypes portray male students as lazy and troublesome and female students as diligent and compliant" (Heyder and Kessels 2015, 476). Our results suggest that gender stereotypes of girls as obedient students, and the piano as being an inherently feminine instrument, must be put to rest. In fact, girls just as frequently as boys are shown to have dropped out of piano, and showed equal deficiencies in practising, progress, musical ability, and how long they imagined themselves continuing lessons. Our results support findings that there are no significant gender differences in children's attitudes toward music experiences (Rife et al. 2001). It is interesting to observe that within the 153 students in the continuing group, boys represent only one third of the total number, which may indicate that fewer boys than girls get involved in piano lessons in the first place, perhaps as the result of gender stereotypes. 
Parental involvement was shown in the literature to be a significant predictor of student dropout (Govel 2004). It was surprising that in our results we found no statistical significance between dropout and continuing group parents' attendance at lessons, contact with the piano teacher, help with home practising, praise and rewards for home practice, or presence at recitals. In fact, the averages suggest that the parents of dropout students helped slightly more with home practice than the continuing parents. One parent wrote that the main reason for quitting lessons was because "practising was a fight." Research with piano students "generally supports the premise that parents" behavioral support impacts student retention" (Chardos-Camilli 2015, 3). Most research encourages the idea that the more parents are involved, the more successful piano lessons become, and that having parents help with home practice is positively related to children's piano lesson outcomes (Comeau and Huta 2015). However, the quality of parental involvement is what seems to be in question here. Studies have shown that "non-intrusive parental support, where parents are not over-invested in the child's future, may be preferable" (Moore, Burland, and Davidson 2003, 544). Since the frequency between the continuing and dropout groups' parental involvement was similar, our results suggest that parents' behaviour may have been somewhat overbearing and contributed to student dropout.

Aside from direct parental involvement, the overall family culture, as viewed through home environment, resulted as a surprisingly strong predictor for dropping out and warrants further research. The literature has, so far, not addressed this topic and our results became exploratory findings. Family culture is a particularly important distinction between piano and other instrumental lessons: the many hours of solitary home practice necessary for mastering the piano are strongly contrasted with school band, where the majority of learning takes place during school hours and has immediate social rewards. Taking private piano lessons requires the support of the entire family, such that children require a focused practice space with few distractions from siblings, a regular practice time without interfering scheduled activities, and encouragement from parents without negative comments about playing too loudly or complaints about repeating the same passage. Research in music education shows that the best musical learning is achieved when parents and teachers work "in concert so that the unique opportunities and special resources of home and school operate simultaneously and cooperatively to positively influence the growth of children" (Brand 1986, 118). Our results suggest that the home environments of the dropout students did not work in tandem with what was being learned at piano lessons. We found that dropout families spent significantly less time listening to classical music, more listening to pop and country, fewer attendances at professional concerts, and less ensemble participation than continuing students. This supports previous findings in which students referred to classical repertoire as others' music-implying that classical music is composed, performed, and enjoyed by adults-and never developed ownership of this style of playing (Williams 2002). It is understandable that a student who has never listened to classical piano repertoire would not find a 
connection to playing that style. By listening to piano music and attending professional concerts, parents are also showing the child that these are things considered valuable, and children do not often get that same message at school or from other activities. This suggests that students involved in classically trained piano lessons must be regularly exposed to various styles of recorded and live piano music by their families. It also seemed that the family culture where quitting was an acceptable option meant that a very high percentage of dropout students' siblings had also started but stopped music lessons. This illustrates a home environment where piano lessons are taken without any serious commitment, and parental attitudes generally allow for lower standards and little follow-through.

\section{Conclusion}

Our study can provide recommendations that teachers and parents may seek to establish before piano lessons begin. By understanding the predictors that affect dropout, we may be able to encourage future parents and teachers to establish learning environments and routines that lead to more successful piano experiences. Parents must become a positive role model and construct a family culture that regularly prioritizes piano music. Students must put in the effort required to nurture their playing ability and develop a notable level of musical achievement. If students can establish a meaningful relationship with piano music, which is supported by their daily home environment, by the time most students reach adolescence and their desire for music lessons begins to decline they may be better equipped to persist through the turbulent pre-teen years.

We acknowledge there were limitations and further questions within this research study. Primarily, the 55 students in the dropout sample were generally homogenous in background: upper-middle-class, Caucasian families from western Canada. Providing a larger sample size with students from varied background and ethnicities may have provided slightly different opinions or insights. We must remember that, as attitudes of adolescents change regularly, this study provides only a snapshot of students' feelings and attitudes at the time of taking the survey, and questions requiring past memories may have been blurred, forgotten, or romanticized. Future research may ask if whether having the right predictors in place before piano lessons commence could affect whether students are more compelled to persist with lessons, given the right environment. Finally, the impact of home culture in students' piano lessons, and its effect on attrition or continuation, is a question that requires further study.

\section{REFERENCES}

Asmus, E.P. (1986). "Student Beliefs about the Causes of Success and Failure in Music: A Study of Achievement Motivation." Journal of Research in Music Education 34 (4): 262-78.

Austin, J., J. Renwick, and G. McPherson. (2006). “Developing Motivation.” In The Child as Musician: A Handbook of Musical Development, edited by G. McPherson, 213-33. New York: Oxford University Press. 
Barry, N. (2007). "Motivating the Reluctant Student." American Music Teacher, $56(5): 23-7$.

Brand, M. (1986). "Relationship between Home Musical Environment and Selected Musical Attributes of Second-Grade Children." Journal of Research in Music Education, 34 (2): 111-20.

- (2001). "Chinese and American Music Majors: Cross-Cultural Comparisons in Motivation and Strategies for Learning and Studying." Psychology of Music 29 (2): 170-8.

Chardos-Camilli, T. (2010). "Parental and Personality Factors That Predict Students' Length of Piano Study.” PhD diss., University of Oklahoma.

_. (2015). "Parental Factors and Personality Traits That Predict Students' Length of Piano Study." Music Teachers National Association e-Journal 6 (3): $2-14$.

Chen, T. (2011). "The 6 Stages of Piano Students: Why and When Piano Students Quit Lessons." Music Memos, https://musicmemos.wordpress. com/2011/o8/19/the- 6 -stages-of-piano-students-why-and-when-piano -students-quit-lessons/.

Comeau, G., and V. Huta. (2015). "Addressing Common Parental Concerns about Factors That Could Influence Piano Students' Autonomous Motivation, Diligence, and Performance." Intersections 35 (1): 27-52.

Comeau, G., V. Huta, and Y. Liu. (2015). "Work Ethic, Motivation, and Parental Influences in Chinese and North American Children Learning to Play the Piano." International Journal of Music Education 33 (2): 181-94.

Cooke, M., and R. Morris. (1996). "Music Making in Great Britain." Journal of the Market Research Society 38 (2): 123-34.

Costa-Giomi, E. (2004). “I Do Not Want to Study Piano!' Early Predictors of Student Dropout Behavior." Bulletin of the Council for Research in Music Education 161-2:57-64.

Costa-Giomi, E., P.J. Flowers, and W. Sasaki. (2005). "Piano Lessons of Beginning Students Who Persist or Drop Out: Teacher Behavior, Student Behavior, and Lesson Progress." Journal of Research in Music Education 53 (3): 234-47.

Cremaschi, a.m., K. Ilinykh, E. Leger, and N. Smith. (2015). "Students Who Quit Music Lessons: Recent Research and Recommendations for Teachers." MTNA e-Journal, 6 (3): 15-26.

Creswell, J. (2015). A Concise Introduction to Mixed Methods Research. Thousand Oaks, CA: Sage.

Croucher, A., and I. Reid. (1981). "Pupil Attitude Changes to Junior School Activities." Research in Education (26 (1): 41-8.

Daniel, R., and J. Bowden. (2013). "The Intermediate Piano Stage: Exploring Teacher Perspectives and Insights." British Journal of Music Education 30 (2): $245-60$.

Evans, P.A. (2009). "Psychological Needs and Social-Cognitive Influences on Participation in Music Activities." PhD diss., University of Illinois at Urbana-Champaign. 
Frakes, L. (1984). "Differences in Music Achievement, Academic Achievement, and Attitude among Participants, Dropouts, and Nonparticipants in Secondary School Music." PhD diss., University of Iowa.

Gagne, F. (1991). "Nature or Nurture? A Re-examination of Sloboda and Howe's (1991) Interview Study on Talent Development in Music." Psychology of Music 27 (1): 38-51.

Gerelus, K., G. Comeau, V. Huta, and M. Swirp. (2019). "Parting Ways with Piano Lessons: Comparing Motivation between Continuing and Dropout Piano Students." Bulletin of the Council for Research in Music Education, Accepted.

Govel, L.S.M. (2004). "An Examination of the Types of Parental Involvement among Piano Student Dropouts." PhD diss., University of Southern California.

Gray, R. (2016). "5 Reasons You Should Let Your Child Quit Piano Lessons.” https://ruthiegray.mom/child-quit-piano-lessons/.

Griswold, P.A., and D.A. Chroback. (1981). "Sex-Role Associations of Music Instruments and Occupations by Gender and Major." Journal of Research in Music Education 29 (1): 57-62.

Heyder, A., and U. Kessels. (2015). "Do Teachers Equate Male and Masculine with Lower Academic Engagement? How Students' Gender Enactment Triggers Gender Stereotypes at School." Social Psychology of Education 18 (3): $467-85$.

Howe, M.J.A., J.W. Davidson, and J.A. Sloboda. (1998). "Innate Talents: Reality or Myth?" Behavioral and Brain Sciences 21 (3): 399-407.

Klinedinst, R.M. (1991). "Predicting Performance Achievement and Retention of Fifth-Grade Instrumental Students." Journal of Research in Music Education 39 (3): 225-38.

Kramer, R. (2016). "Walk a Mile in Your Neighbor's Shoes: Gender Issues in Piano Teaching." Clavier Companion 8 (3): 42-4.

Mawbey, W.E. (1973). "Wastage from Instrumental Classes in Schools." Psychology of Music 1 (1): 33-3.

McCarthy, J.F. (1980). "Individualized Instruction, Student Achievement, and Dropout in an Urban Elementary Instrumental Music Program." Journal of Research in Music Education 28 (1): 59-69.

McPherson, G.E. (2000). "Commitment and Practice: Key Ingredients for Achievement during the Early Stages of Learning a Musical Instrument." Bulletin of the Council for Research in Music Education 147:122-7.

McPherson, G.E., and J.W. Davidson. (2002). "Musical Practice: Mother and Child Interactions during the First Year of Learning an Instrument." Music Education Research 4 (1): 141-56.

McPherson, G.E., and S.A. O’Neill. (2010). “Students' Motivation to Study Music as Compared to Other sShool Subjects: A Comparison of Eight Countries." Research Studies in Music Education 32 (2): 101-37.

McPherson, G.E., M.S. Osborne, M.S. Barrett, J.W. Davidson, and R. Faulkner. (2015). "Motivation to Study Music in Australian Schools: The Impact of 
Music Learning, Gender, and Socio-economic Status." Research Studies in Music Education 37 (2): 141-60.

Merwin, K. (2014). “Top Ten Reasons for Letting Your Child Quit Piano.” Clavier Companion 6 (4): 9.

Moore, D.G., K. Burland, and J.W. Davidson. (2003). "The Social Context of Musical Success: A Developmental Account." British Journal of Psychology $94(4), 529-49$.

Moore, K. (2012). "Why Do Children Drop Out of Piano Lessons?" Coppelpianoshop, https://coppellpianoshop.wordpress.com/2012/02/o8/ why-do-children-drop-out-of-piano-lessons/.

North, A.C., D.J. Hargreaves, and S.A. O’Neill. (200o). “The Importance of Music to Adolescents." British Journal of Educational Psychology 70 (2): $255-72$.

Power, K.M. (1990). “A Cross-Cultural Study of Mothers' and Teachers' Attitudes toward Music Education in the U.S.A. and Japan." PhD diss., University of Hawaii.

Rife, N.A., Z.M. Shnek, J.L. Lauby, and L. Blumberg Lapidus. (2001). "Children's Satisfaction with Private Music Lessons." Journal of Research in Music Education 49 (1): 21-32.

Royal Conservatory of Music. (2008). Piano Syllabus: 2008 Edition. Toronto: Fredrick Harris Music.

Seo, H.-K.B. (2010). "Motivating K-12 Students in Private Piano Lessons Based on Individual Backgrounds." PhD diss., University of Mississippi.

Van Cleave, T. (2010). "Perceptions of Studio Based Music Teachers regarding Recruitment and Retention of Students" PhD diss., Ball State University.

Williams, K. (2002). "Attrition in Applied Music Study: Three Retrospective Case Studies." Update: Applications of Research in Music Education 21 (1): 1-9.

Yang, M. (2009). Review of Musicians from a Different Shore: Asians and Asian Americans in Classical Music. Popular Music and Society 32 (2): 293-5.

Young, W.T. (1971). "The Role of Musical Aptitude, Intelligence, and Academic Achievement in Predicting the Musical Attainment of Elementary Instrumental Music Students." Journal of Research in Music Education 1 (4): $385-98$.

\section{ABSTRACT}

Dropping out of piano lessons before reaching a moderate mastery of the instrument is a frequent problem among students. Previous research finds that children often leave music lessons as the result of predictors such as expertise-measured by musical ability, academic achievement, and musical achievement-and environment-measured by social and educational status, gender differences, parental involvement, and home culture. Fifty-five former piano students and their parents filled out questionnaires with Likert-scale, multiple choice, and open-ended questions in a mixed-methods study. This group was compared to 153 students and parents who were still involved with 
lessons. The results between the two groups show that many of the attrition factors outlined in the literature predicted piano student dropouts as well.

\section{RÉSUMÉ}

Abandonner les cours de piano avant d'atteindre une maîtrise raisonnable de l'instrument est un problème fréquent parmi les étudiants. De précédentes recherches ont montré que les enfants décrochent des leçons de musique à la lumière de facteurs tels que l'expertise - mesurée par l'habilité musicale, l'accomplissement académique, et l'accomplissement musical - et l'environnement - mesurée le statut social et éducationnel, les différences de genre, l'investissement parental, et la culture à la maison. Cinquante-cinq anciens étudiants en piano et leurs parents ont rempli des questionnaires contenant des questions selon l'échelle de Likert, à choix multiple, et à réponse ouverte dans le cadre d'une étude en méthodes mixtes. Ce groupe a été comparé à cent cinquante-trois étudiants et parents qui poursuivaient encore leurs leçons. Les résultats entre ces deux groupes montrent que plusieurs facteurs d'attrition soulignés dans la littérature ont également prédit le décrochage des étudiants en piano.

\section{BIOGRAPHIES}

Karen Gerelus is a doctoral candidate at the University of Calgary researching musical identity and motivation with piano students. She holds degrees from the University of Saskatchewan, the University of Ottawa, the Royal Conservatory of Music, and Trinity College London. Her research has been featured across North America at conferences, in print, and on podcasts. She is a third-generation piano teacher with an active private studio where she teaches piano, pedagogy, music history, and theory.

Gilles Comeau, professor at the School of Music of the University of Ottawa, co-ordinates the piano pedagogy and the music education sectors. Dr. Comeau has been the beneficiary of many research grants, including a large grant from the Canadian Foundation for Innovation to set up a research laboratory in piano pedagogy. As head of this infrastructure, he has established partnerships with many other research laboratories and set up multidisciplinary research groups that study piano learning and piano teaching.

Mikael Swirp earned a BSc in mechanical engineering in Calgary and completed his licentiate with Trinity College London in piano performance. This combination of music and engineering is well suited to his role in the Piano Pedagogy Research Laboratory at the University of Ottawa. He is responsible for the technical aspects of the operation of the lab, as well as collaborating with researchers. 